\title{
UMA FÁBRICA DE CORDAS NO RIO DE JANEIRO DOS VICE-REIS: \\ O BENEFICIAMENTO DO LINHO GUAXIMA POR JOÃO HOPMAN (C.1777-C.1789)
}

ALEXANDER REIS *

UNIVERSIDADE FEDERAL DO ESTADO DO RIO DE JANEIRO

RIO DE JANEIRO - RIO DE JANEIRO - BRASIL

Na segunda metade do século XVIII ocorreu uma diversificação na exportação agrícola na cidade do Rio de Janeiro. Os vice-reis Marquês de Lavradio e Luís de Vasconcelos e Sousa incentivaram experiências para a produção de cordas, sacos e lonas a partir da fibra de um arbusto de nome popular chamado guaxima. A maior parte dos autores informa que a fábrica de linho guaxima não obteve êxito, de fato, esse linho não se tornou um item de exportação, mas foi fabricado para consumo local. O intuito deste artigo é dialogar com pesquisas históricas sobre o tema, RESUMO rastrear a memória sobre a cordoaria em jornais do século XIX e analisar documentos dos representantes régios sobre a produção e o consumo local. Por fim, identificar o artefato utilizado, analisar as técnicas de produção e as experiências de resistência dessa corda de linho guaxima em comparação com a corda de linho cânhamo.

Palavras-chave: Linho Guaxima; Fábrica de Cordas; Diversificação Agrícola.

En la segunda mitad del siglo XVIII ocurrió una diversificación de las exportaciones agrícolas en la ciudad de Rio de Janeiro. Los virreyes Marquês de Lavradio y Luís de Vasconcelos e Sousa fomentaron experimentos en la producción de cuerdas, bolsas y lonas a partir de la fibra de un arbusto de nombre popular llamado guaxima. La mayoría de los autores informa que la fábrica de lino guaxima no tuvo éxito, de hecho, este lino no se convirtió en un producto de exportación, sino que se fabricó para el consumo local. El propósito de este artículo es dialogar con la investigación histórica sobre el tema, rastrear la memoria de la fábrica de cuerdas en los periódicos del siglo XIX y analizar documentos de representantes reales sobre la producción y el consumo local. Finalmente, identificar el artefacto utilizado, analizar las técnicas de producción y experimentos de resistencia de esta cuerda de lino de guaxima en comparación con la cuerda de lino de cáñamo.

Palabras-clave: Lino Guaxima; Fábrica de Cuerdas; Diversificación Agrícola.

\footnotetext{
* Formado em História pela Universidade do Estado do Rio de Janeiro (UERJ). Mestrando do Programa de Pós-Graduação em História pela Universidade Federal do Estado do Rio de Janeiro (UNIRIO). E-mail: alexanderlimareis@ @otmail.com.
} 


\section{INTRODUCÃO}

O linho guaxima foi pouco estudado pela historiografia brasileira. É geralmente mencionado como um gênero que fez parte da diversificação agrícola que ocorreu no Rio de Janeiro no final do século XVIII. João Hopman foi o principal agente que contribuiu para o desenvolvimento da cultura desse linho em solo fluminense. Ele é um personagem relativamente conhecido da história do Brasil por conta da sua atuação na produção cafeeira. A sua vocação comercial e intelectual colaborou para o incremento de novos gêneros agrícolas, visto que a política metropolitana passou a incentivar o estudo, o reconhecimento e o desenvolvimento de tais gêneros para entrar na pauta de exportação. Muitos produtos exóticos ou de menor interesse foram alvo de suas experiências para saber se poderia se tornar item de comércio. É o caso da canela que a sua mulher e filhas continuaram realizando exportação, mesmo após a sua morte em 1789. Outro exemplo isolado, mas, no mínimo interessante, é o envio de uma planta de baunilha, em 1776, para o capitão de mar e guerra João Nicolau Semerckell. Na carta que seguiu junto à planta foi possível perceber que João Nicolau esteve no Rio de Janeiro em contato com o remetente, pois nela é recordado que o capitão em sua despedida pediu que enviasse um exemplar da planta baunilha. Além disso, ainda informa que enviou o espécime, procedendo da mesma forma como enviou os abacaxis em momento anterior. Esta informação é relevante para pensar o seu envolvimento com os diversos gêneros agrícolas ${ }^{1}$.

Antes de iniciar a narrativa sobre suas atividades na cordoaria do linho guaxima é necessário explicar, em linhas gerais, a conjuntura política, econômica e cultural da época. João Hopman não é um caso excepcional. Outros agentes também tinham aptidão e desenvolveram novas técnicas de cultivo e beneficiamento agrícola ${ }^{2}$. Nas palavras do historiador Arno Wehling: era o momento em que ocorreu o fomentismo português. De acordo com esse historiador, a política econômica visou renovar a produção agrícola e, consequentemente,

\footnotetext{
${ }^{1}$ ARQUIVO HISTÓRICO ULTRAMARINO (AHU) -Rio de Janeiro, cx. 108, doc. 22. AHU_ACL_CU_017, Cx. 99, D. 8515.

${ }^{2}$ É o caso de Jerônimo Vieira de Abreu que atuou no cultivo e beneficiamento de diversos produtos agrícolas. Os dois se tornaram inspetores da Mesa da Inspeção do Rio de Janeiro em 1783. João Hopman foi nomeado inspetor do comércio e Jerônimo Vieira de Abreu inspetor da agricultura. Conferir em: Os inspetores da Mesa de Inspeção do Rio de Janeiro: Jerônimo Vieira de Abreu e João Hopman (1783-c.1800). ANAIS DO $17^{\circ}$ SEMINÁRIO NACIONAL DE HISTÓRIA DA CIÊNCIA E DA TECNOLOGIA, 2020.
} 
incentivar novas culturas, que surgiram a partir de 1760 por causa da oscilação no preço do açúcar, do declínio da extração de minerais, entre outros ${ }^{3}$.

Em relação ao panorama intelectual da cidade do Rio de Janeiro, duas academias científicas incentivaram o estudo de História Natural nesse período. Esses espaços foram importantes por proferir novas ideias sobre as ciências e a natureza. A primeira academia foi criada no período do vice-rei Marquês de Lavradio e a segunda no vice-reinado seguinte, de Luís de Vasconcelos e Sousa. Os integrantes dessas academias tinham contato com acadêmicos de Portugal e de outras nações. O movimento iluminista estava em pleno desenvolvimento no período e os integrantes das academias na América portuguesa faziam parte desta rede de conhecimento. Os principais membros da primeira academia eram o presidente e médico José Henriques Ferreira que escreveu uma memória econômica sobre o linho guaxima, analisada mais à frente. Os diretores Antônio Ribeiro de Paiva, boticário; Maurício da Costa, cirurgiãomor; e o irmão do presidente, Manoel Joaquim Henriques de Paiva, boticário ${ }^{4}$.

Na segunda metade do século XVIII, as academias científicas tinham por intuito estudar os três reinos da natureza (flora, fauna e mineralogia) para fins medicinais, alimentação e, especialmente, para promoção de novas mercadorias para o comércio. No contexto do Iluminismo o conhecimento útil passou a ser mais valorizado pelos intelectuais: “[...] a história natural europeia firmou-se, a partir de meados do século XVIII, exatamente com a crítica do conhecimento diletante" $"$. Além disso, essas ideias não ficaram restritas ao conhecimento de filósofos e universidades. Foi o momento em que o conhecimento teórico cedeu lugar ao conhecimento das oficinas e do trabalho artesanal. As próprias práticas administrativas carregaram no seu âmago o novo paradigma da História Natural ${ }^{6}$.

De acordo com a farmacêutica e historiadora Vera Regina Beltrão Marques, no texto Escola de homens de ciências: a Academia Científica do Rio de Janeiro, 1772-1779, o intelectual português Antônio Ribeiro Sanches foi quem enviou as primeiras notícias ao

\footnotetext{
${ }^{3}$ WEHLING, Arno. O fomentismo português no final do século XVIII: doutrinas, mecanismos, exemplificações. RIHGB, v. 316, p.170-279, 1977.

${ }^{4}$ PATACA, Ermelinda M. Terra, água e ar nas viagens científicas portuguesas (1755-1808). Tese de Doutorado. São Paulo: Instituto de Geociências/UNICAMP, 2006.

${ }^{5}$ KURY, Lorelai. Homens de ciência no Brasil: impérios coloniais e circulação de informações (1780-1810). História, Ciências, Saúde Manguinhos, v. 11, s. 1, 2004.

${ }^{6}$ KURY, 2004
} 
taxonomista e botânico sueco Carl von Linné sobre a fundação da Academia Científica do Rio de Janeiro ${ }^{7}$. A troca de correspondência entre membros das academias com intelectuais de outras nações é evidência de uma relação que extrapola o modelo clássico de interação colônia/metrópole. É importante destacar as academias como espaço de interação intelectual. Esse contato agremiativo era uma das formas de apreender como grupos sociais, mesmo sem uma instrução formal universitária, acessavam determinadas discussões e conhecimentos, pois João Hopman foi convidado pelo marquês para participar dessa academia como pode ser conferido no livro Rio de Janeiro setecentista, do historiador urbanista Nireu Cavalcanti ${ }^{8}$.

A partir da documentação oficial dos vice-reis Marquês de Lavradio (1769-1779) e Luís de Vasconcelos e Sousa (1779-1790) é possível compreender a atuação desses representantes régios e a articulação de grupos sociais distintos para promover o desenvolvimento de novos produtos para exportação. As atividades administrativas permitem acessar a ação concreta de diversos agentes ligado direta ou indiretamente a administração imperial. Desta forma, o artigo tem por objetivo apresentar as atividades de João Hopman em relação a cultura do linho guaxima, desde o início das experiências, testes, estabelecimento da fábrica até as negociações dos vice-reis com a Corte portuguesa para promover a exportação e o consumo local do linho guaxima.

A primeira parte do texto foi destinada a apresentar os principais trabalhos que dialogaram com as atividades do personagem no beneficiamento deste linho. Em seguida, buscou-se perceber como a cordoaria esteve presente em alguns jornais no decorrer do século XIX. Por fim, intentou-se fazer uma análise das fontes da época sobre o tema com intuito de responder algumas questões provocadas pelos textos historiográficos consultados para esta pesquisa. Na época, o linho de cânhamo era o principal linho utilizado para a confecção de cordas para embarcações e outros usos. A cronologia se inicia em c. 1777, ano em que ocorreu uma escassez desse linho, como consta em uma carta de Luís de Vasconcelos e Sousa analisada adiante. Em uma atmosfera intelectual de reformas e incentivo de estudos da face científica e prática do Iluminismo, sobretudo da botânica, propôs-se uma forma alternativa de suprir esse

${ }^{7}$ MARQUES, Vera R. B. Escola de homens de ciências: a Academia Científica do Rio de Janeiro, 1772-1779. Editora UFPR: Educar, Curitiba, n. 25 , p. 39-57, 2005.

${ }^{8}$ CAVALCANTI, Nireu. $O$ Rio de Janeiro setecentista: a vida e a construção da cidade da invasão francesa até a chegada da Corte. Rio de Janeiro: Zahar, 2004. 
escasseamento, uma vez que pessoas escravizadas em fazendas e indígenas já tinham conhecimento do linho guaxima e utilizavam para amarrar animais. Além do mais, a carta com as primeiras notícias sobre o linho guaxima e a solicitação para o estabelecimento de uma fábrica de cordas é datada de 12 de janeiro de 1778. Nesse sentido, supõe-se que os experimentos foram iniciados antes deste ano. O recorte final foi delimitado em 1789, ano de falecimento de João Hopman e que coincidiu com o término do vice-reinado de Luís de Vasconcelos e Sousa.

\section{A HISTORIOGRAFIA SOBRE O LINHO GUAXIMA}

Na historiografia não há consenso sobre a nacionalidade de João Hopman. Há textos que o apresentam como inglês e outros como holandês. Eugénio da Cunha e Freitas recuperou informações sobre a ascendência de João Hopman em comunicação intitulada Familiares do Santo Ofício do Porto publicada na Revista de História em 1979. Eugénio Freitas explica que a admissão ao Santo Ofício era precedida de um inquérito rigoroso sobre o proponente e sua família para saber se podiam viver com os próprios recursos e manter os costumes. Além disso, não podia ter 'sangue' de judeu ou mourisco. O final do inquérito resultava em uma carta de representação social que muitas famílias requisitavam para viver ou exercer atividades fora da sede do reino português. Essa comunicação é importante por conter o local de nascimento de João Hopman. Ele requisitou um desses inquéritos como atesta Eugénio Freitas: “Até os estrangeiros o faziam. Lembro do caso de um João Hopman, nascido no Porto, filho de ingleses Sibrando Hopman e Doroteia Wittingham que antes de se dirigir ao Rio de Janeiro obteve carta de familiar em 1744",

Sabe-se que João Hopman veio para o Rio de Janeiro em c. 1750. A tese do economista e historiador Fábio Pesavento, intitulada Um pouco antes da Corte: a economia do Rio de Janeiro na segunda metade do Setecentos, foi o trabalho que possibilitou o maior número de informações sobre a vida de João Hopman, especialmente sobre a complexidade das relações comerciais em que o personagem atuou como articulador dos interesses de homens de negócio

${ }_{9}^{9}$ FREITAS, Eugénio Cunha e, Familiares do Santo Ofício no Porto, Revista de História, Porto, v.2, pp. 229-236,1979, p. 230. 
holandeses que comercializavam na cidade do Rio de Janeiro. João Hopman fazia parte de uma rede de comerciantes holandeses: “[...] responsável por cobranças e agencias para Radmaker \& Cia em duas oportunidades, na década de 1760. Ao total, foram encontrados doze negociantes holandeses atuantes em Lisboa e com negócios no Rio de Janeiro na segunda parte do XVIII"10.

Embora haja ainda controvérsia sobre a nacionalidade de João Hopman no registro de vários autores, sabe-se que ele era natural da cidade do Porto. Já a nacionalidade de seus progenitores ainda continua em aberto. Eugénio Freitas, no entanto, informa que eram ingleses. Uma possiblidade é a de que sua mãe seja inglesa, porque o seu sobrenome, Wittingham, referese a uma antiga paróquia e região da Inglaterra. Entretanto, Fábio Pesavento encontrou documentos que comprovam que seu pai era natural da cidade de Armsterdam assim como seu avô paterno Gil Hopman.

Em 1744, quando solicitou a carta ao Santo Ofício, João Hopman vivia em Lisboa e sua idade pode ser consultada nesta passagem: "[...] representava ter a idade de mais de 20 anos. Ainda em 1744, era assistente em Lisboa e morador na mesma cidade, na rua da Bica do Arte Bello em casa de João Henrique Martins"11. Ele chegou ao Rio de Janeiro por volta de 1750 e ali viveu até o fim de sua vida, em 1789. Poucas informações foram encontradas sobre o início da sua trajetória em solo fluminense. Fábio Pesavento informa que João Hopman casou-se, aproximadamente em 1752, com Maria Caetana, nascida no Rio de Janeiro: “[...] Maria é filha de João Carneiro da Silva (natural da cidade do Porto) e Izabel Maria Nacentes (natural do Rio de Janeiro)"12. Esse laço matrimonial facilitou a entrada de João Hopman no comércio fluminense.

No Arquivo Histórico Ultramarino (AHU) consta um ofício do vice-rei Conde da Cunha, datado de 1765, em que é mencionado o nome de João Hopman. Na carta consta a informação que, naquele mesmo ano, João Hopman exportava barbatanas, pipas e barricas de azeite de baleia ${ }^{13}$. A carta foi enviada ao secretário de Estado, Francisco Xavier de Mendonça

\footnotetext{
${ }^{10}$ PESAVENTO, Fábio. Um pouco antes da Corte: a economia do Rio de Janeiro na segunda metade do Setecentos. Tese (Doutorado em Ciências Econômicas) - Universidade Federal Fluminense, Niterói, 2009, p. 126, grifo do autor.

${ }^{11}$ PESAVENTO, 2009, p. 151.

${ }^{12}$ PESAVENTO, 2009, p. 151

${ }^{13}$ Nessa época, João Hopman era sócio de José do Couto Pereira e de João Carneiro da Silva.
} 
Furtado, com o intuito de que se realizasse uma inspeção na carga para possível apreensão de contrabando, a qual seguiu para Lisboa na embarcação Nossa Senhora do Porto e São José ${ }^{14}$.

Após esta breve consideração biográfica, inicia-se o diálogo entre textos que, de alguma forma, mencionaram a cordoaria de linho guaxima. Em 1955, o professor da Faculdade de Filosofia, Ciências e Letras da Universidade de São Paulo, Manuel Nunes Dias escreveu pequeno texto chamado Notícia da cultura industrial da guaxima no Brasil nos fins do século $X V I I I$, no qual organizou-se uma cronologia sobre a produção do linho guaxima. O autor explica que não há documentos da época sobre a produção desta cultura antes de 1778. Em relação à planta, ele descreve que é muito comum na cidade e cresce com facilidade em diversos tipos de solos. É uma planta/arbusto têxtil da Família da Malváceas ${ }^{15}$. Boa parte das fontes informam a abundância e a facilidade de cultivo deste linho. Nunes Dias descreve que o arbusto pode atingir 15 palmos (i.e., 3 metros $\cong$ ).

O linho guaxima era útil para produzir cordas, tipos de sacos e lonas. Manuel Nunes Dias menciona que a fibra comparada ao linho cânhamo era mais vantajosa por ter menos peso e ser mais resistente. Essas informações estão presentes na primeira carta em que o marquês apresenta o linho para a Corte portuguesa. Mas, as experiências comparativas entre os linhos ainda não tinham sido executadas, demonstrando que o marquês buscava persuadir seus interlocutores ao apresentar a utilidade do linho guaxima. Na época, as cordas das embarcações eram providas pelo beneficiamento de linho cânhamo, sobretudo, na cidade de Riga, capital da Letônia: “[...] até os fins do século XVIII ao ponto dos navios da rota do Brasil serem um sorvedouro de cordames importados dos mercados industriais do Mar do Norte"16. Dias não encontrou documentos que comprovassem que a Rainha Maria I tivesse autorizado a produção e o privilégio exclusivo, nem informações de funcionamento da cordoaria: "Tampouco se sabe se a exportação da guaxima para o Reino era feita apenas em linho em rama, ou se a fibra já ia industrializada $[. . .]^{\prime 17}$. Um dos intuitos deste texto é aprofundar esta análise e indagações:

\footnotetext{
${ }^{14}$ AHU, Rio de Janeiro, cx. 81, doc. 11 AHU_ACL_CU_017, Cx. 74, D. 6744.

15 O nome científico da planta é Hibiscus pernambucensis Arruda. No livro de Harri Lorenzi Árvores brasileiras constam três plantas popularmente chamadas de guaxima, duas da Família Sterculiaceae chamadas de 'guaxima macho' e 'guaxima torcida'; uma da Família Malvaceae 'guaxima do mangue'. Há também uma planta chamada guaxima de nome científico Urena lobata também da Família da Malvaceae utilizada para produção de fibra.

${ }^{16}$ DIAS, Manuel Nunes. Notícias da cultura industrial da guaxima no Brasil nos fins do século XVIII. Revista de História. v. 11, n. 24, pp. 419-423, 1955, p. 421.

${ }^{17}$ DIAS, 1955, p. 422.
} 
Teria tido melhor sorte o novo Vice-rei, D. Luís de Vasconcelos e Sousa? Nada se sabe. $\mathrm{O}$ desconhecimento que se tem sobre isto, restringe mais ainda, a intenção deste alinhavado-artigo que, simplesmente, se propõe chamar atenção da nossa historiografia para um assunto que não só por nos parecer ignorado, mas por o julgarmos importante merece futuras pesquisas. Não apenas à História Econômica Colonial do Brasil, mas à nossa própria flora, se daria nova contribuição. ${ }^{18}$

Quinze anos depois, em 1970, o político e escritor Heitor Ferreira Lima publicou o livro História político-econômica e industrial do Brasil, no qual há uma seção sobre construção naval que nos remete aos tempos coloniais. Na parte que cabe à indústria náutica, o autor resume que “[...] é digna de menção a fábrica de cordas de guaxima ou guaxuma, no tempo do marquês de Lavradio, por ele animada, que existiu no Rio de Janeiro, da qual era proprietário João Hopman, produzindo excelente enxárcia"19. Ferreira Lima comparou o linho guaxima com o linho cânhamo produzido na cidade de Riga e concluiu que, ainda que as experiências tenham sido desfavoráveis, o vice-rei não deixou de estimular a produção para uso na cidade do Rio de Janeiro. Ele cita a obra No Rio de Janeiro dos Vice-reis de Afonso de Escrognolle Taunay que permite acessar uma pista para o uso desse linho em embarcações a partir do relato de um viajante espanhol Juan Francisco Aguirre que seguia para a cidade de Assunção, no atual Paraguai, com a incumbência de atuar na demarcação de fronteira entre Portugal e Espanha no ano de 1783. Ao passar pelo Rio de Janeiro: “[...] viu na baía da Guanabara uma corveta portuguesa cujas enxárcias e cabos eram de guaiambé e piaçava, mas que Taunay acha terem sido cordoalha de guaxima, o que demonstra ter dado certo a experiência de Lavradio [...]"20. De fato, as experiências iniciaram no período do Marquês de Lavradio, mas a produção prosseguiu e obteve êxito no vice-reinado de Luís de Vasconcelos e Sousa, como será abordado mais à frente.

Na obra supramencionada, O fomentismo português no final do século XVIII: doutrinas, mecanismos, exemplificações, a história do linho guaxima está atrelada à do linho cânhamo, sendo as vezes difícil de separá-las já que ambos os linhos são de cordoaria. Ao listar as

\footnotetext{
${ }^{18}$ DIAS, 1955, p. 423.

${ }^{19}$ LIMA, Heitor Ferreira. História político-econômica e industrial do Brasil. São Paulo: Companhia Editora Nacional, 1970 , p. 80.

${ }^{20}$ LIMA, 1970, p. 29.
} 
principais pesquisas sobre o final do século XVIII, Arno Wehling elenca o trabalho analisado acima de Manuel Nunes Dias como referência ${ }^{21}$. Em seguida o linho reaparece já no final do trabalho no subcapítulo A primeira fase fomentista: Lavradio e Vasconcelos. Aqui é interessante notar que o linho reaparece no vice-reinado de Luís de Vasconcelos e Sousa: “[...] Hopman foi igual prestigiado, continuando suas experiências com a guaxima, o café e a cochonilha: logo Vasconcelos o encarregaria de pesquisar o urucu" ${ }^{22}$. Já a política econômica do vice-rei Marquês de Lavradio foi resumida na seguinte sentença: "Mereceram atenções especiais, por motivos diversos, o açúcar, o tabaco, o arroz, o trigo e as madeiras, sobretudo o tapinhoã"23. A assertiva de Arno Wehling sobre as novas culturas e a alocação do beneficiamento do linho guaxima no governo de Vasconcelos e Sousa corrobora com a hipótese deste trabalho. Nas narrativas é consensual de que a fábrica de cordas foi fomentada e idealizada sob os auspícios do Marquês de Lavradio, entretanto em 1778 já era o final do mandato do marquês. Embora as experiências tenham prosseguido na década de 1780, o período entre 177782, congregou os desafios, as experiências e os testes que engendraram conhecimento, porém o funcionamento automatizado ocorreu na década seguinte no vice-reinado de Luís de Vasconcelos e Sousa.

João Hopman foi mencionado em dois momentos no livro $O$ Rio de Janeiro setecentista de Nireu Cavalcanti. Primeiro na seção sobre Fábricas Proibidas, em que são listados de maneira breve as fábricas de anil, arroz, fábricas têxteis de tecidos grossos, pequenas oficinas de pentes, guarda-sóis e a fábrica de corda. A outra menção está na seção sobre a Academia Científica do Rio de Janeiro, já mencionada aqui quando Hopman foi convidado para participar da agremiação ${ }^{24}$. Do mesmo modo procedeu a historiadora portuguesa Maria Beatriz Nizza da Silva no livro Cultura letrada e cultura oral no Rio de Janeiro dos vice-reis, cuja abordagem é comum em obras monumentais que tendem ao registro mais geral dos fatos. João Hopman é mencionado quando a autora narra as atividades dos vice-rei Marquês de Lavradio para produzir o linho guaxima. Ela assevera que a Corte portuguesa não se interessou em substituir o linho cânhamo por se tratar de um produto tradicional no ramo da cordoaria. João Hopman reaparece

\footnotetext{
${ }^{21}$ WEHLING, 1977, pp. 180-81.

${ }^{22}$ WEHLING, 1977, p. 247.

${ }^{23}$ WEHLING, 1977, p. 242.

${ }^{24}$ NIREU, 2004.
} 
no final da obra quando recebe o cargo de deputado do comércio para atuar na Mesa de Inspeção em $1783^{25}$.

Na tese já mencionada de Fábio Pesavento, o linho guaxima aparece brevemente na seção sobre indústrias do Rio de Janeiro e depois na parte sobre construção naval. O autor estava interessado em estudar as novas culturas que fizeram parte da diversificação agrícola voltada para a exportação. João Hopman é retratado no contexto dessa diversificação agrícola e detalhadamente estudado na seção sobre trajetórias e agências de alguns homens de negócios do Rio de Janeiro da época. O linho guaxima reaparece na seção que retrata as novas culturas que não tiveram êxito para exportação, precisamente a cochonilha e o linho cânhamo, já o linho guaxima é retratado indiretamente, possivelmente porque não se tornou pauta de exportação ${ }^{26}$.

O brasilianista estadunidense Dauril Alden, por sua vez, dedica uma seção ao tema do processamento de fibras, na qual o linho guaxima e os idealizadores da cordoaria são mencionados, no livro Royal Government in Colonial Brazil. O autor infere que as tentativas do marquês com intuito de produzir cordas para exportação foram inúteis, porém ele não considerou o consumo interno do linho. De maneira geral, a abordagem dele não é diferente para os novos fomentos agrícolas, cujo fim é sempre apresentado de maneira desastrosa ${ }^{27}$. De modo que, logo após as investidas para torná-lo um produto de pauta de exportação, o autor conclui, que tanto o linho quanto o dirigente da fábrica foram esquecidos. O que foi considerado como esquecimento? Se o esquecimento se refere à produção do linho para exportação, a sentença ganha sentido. Entretanto, a afirmação perde sentido ao rastrear as formas de recordação sobre esses eventos em jornais do século XIX e, em particular, o uso dos dados que resultaram das experiências no Rio de Janeiro e Lisboa para testagem da resistência da corda publicada em uma memória econômica na Academia Real das Ciências de Lisboa.

As obras deste tópico foram consultadas na tentativa de compreender como a historiografia havia concebido essa fábrica de linho guaxima. Por conseguinte, busca-se rastrear publicações em periódicos digitalizados na Biblioteca Nacional do Rio de Janeiro com informações sobre essa fábrica de cordas. A partir do sistema de busca digital por palavras foi

\footnotetext{
${ }^{25}$ SILVA, Maria Beatriz N. da. Cultura letrada e cultura oral no Rio de Janeiro dos vice-reis. São Paulo: Editora Unesp, 2013 26 PESAVENTO, 2009.

${ }^{27}$ ALDEN, Dauril. Royal Government in Colonial Brazil. University of California Press, 1968.
} 
possível localizar um conjunto de matérias sobre a atuação dos vice-reis e de João Hopman para estabelecer a cordoaria na cidade do Rio de Janeiro. Embora de forma descontínua, vez por outra, as ações dos representantes régios e de João Hopman foram publicadas em alguns periódicos do século XIX.

\section{A MEMÓRIA DA FÁBRICA DE CORDOARIA PUBLICADA EM ALGUNS JORNAIS DO SÉCULO XIX}

As formas de um historiador interpretar e fazer uso de um documento histórico mudou muito no decorrer do século XX. Para utilizar jornais como fonte de conhecimento sobre o passado, uma orientação metodológica pode ser consultada no texto A história dos, nos e por meio dos periódicos. Nele, a historiadora Tânia Regina de Luca discute a utilização do jornal como fonte pela historiografia. A autora elaborou uma revisão bibliográfica sobre o uso de documento jornalístico como forma de acessar o passado, reconhecendo que toda matéria é produto de uma época e transmite a visão de mundo do contexto de produção. Nesse sentido, para não ser conduzido pelas intenções dos produtores das fontes, é necessário ter noção de quem escreveu e a quem se destina o conteúdo. Essas são ferramentas que ajudam a compreender o contexto em que foi produzido determinada matéria. Então, faz-se necessário: “[...] alertar para o uso instrumental e ingênuo que tomava os periódicos como meros receptáculos de informações a serem selecionadas, extraídas e utilizadas ao bel prazer do pesquisador" 28 .

É consenso que há influências e tensões implícitas no texto jornalístico como qualquer outra produção de texto. Neste artigo, pretende-se afastar dessa análise ingênua que apreende como verdade o registro, mas, ao mesmo tempo, não convém para esta narrativa trazer à tona toda a complexidade ideológica e de interesses que envolve uma revista/jornal como plataforma de comunicação. De maneira cronológica, buscou-se percorrer alguns periódicos com intuito

\footnotetext{
${ }^{28}$ LUCA, Tânia Regina de. A história dos, nos e por meio dos periódicos. In: PINSKY, Carla Bassanezi (Org.). Fontes Históricas. São Paulo: Contexto, 2005, p. 116
} 
de perceber como a memórias sobre o personagem, em análise e a fábrica de linho guaxima foram concebidas pela posteridade.

O jornal Sete D'Abril, publicado em 1834, elencou uma série de fomentos fabris no período em que D. João VI esteve no Brasil. Algumas linhas foram destinadas para falar sobre a produção de linho. Na matéria é narrada a produção de pólvora no Rio de Janeiro e de ferro em São Paulo. Ao mencionar a produção do linho, a matéria indaga ao leitor se tinha conhecimento das experiências elaboradas por João Hopman décadas antes. A matéria informa que as experiências com as cordas de linho guaxima versus as cordas de linho cânhamo obtiveram: “[...] bons resultados comparativos com os cabos de linho de igual grossura que se tem em uma memória por ele oferecida a Academia de Lisboa, julgada digna de se publicar $[\ldots]^{\prime 29}$. No decorrer da pesquisa não foi encontrada uma memória de autoria de João Hopman. A memória mencionada pelo jornal pode ser da Academia Real das Ciências de Lisboa, publicada no ano de falecimento de Hopman, em 1789. Essa memória econômica é de autoria do médico do marquês e presidente da Academia Científica, José Henriques Ferreira. Entretanto, os dados das experiências de resistência dos linhos que constam na tabela da memória econômica são os mesmos que constam em um manuscrito de João Hopman e em um anexo de uma carta do desembargador da Relação e provedor da Fazenda Real João Antônio Salter de Mendonça.

Tal matéria do jornal Sete D'Abril permite recuperar o texto da Tânia Regina de Luca sobre o jornal como fonte, devido as severas críticas sobre esses empreendimentos. Aqui é preciso relacionar de certo modo com o contexto de instabilidade política do início do período regencial. Um trabalho aprofundado pode recuperar o editorial e o que estava acontecendo em outubro de 1834, bem como saber quem financiava o jornal e a que leitores se destinava. A matéria critica a forma simbólica do uso do linho cânhamo ao mencionar que o governo não sabe produzir o linho cânhamo e só o utiliza como item de exposição em museu. Ao mesmo tempo criticou a produção porque foi conduzida pelo Estado: "Feitorias de linho cânhamo por conta da Fazenda Pública! ... Isto faz rir por um olho e chorar por outro!"30.

\footnotetext{
${ }^{29}$ Sete D'Abril, 1834, edição 191, p. 2.

${ }^{30}$ Sete D'Abril, 1834 edição 191, p. 1.
} 
Em 1844, o jornal Correio Official publicou na íntegra a memória econômica sobre o linho guaxima de José Henriques Ferreira. É curioso notar que o uso inicial do linho é atribuído, tanto nesta matéria quanto na memória econômica, aos conhecimentos de 'homens do campo'. Contudo, na primeira carta do marquês consta que os negros de fazendas e alguns indígenas utilizavam esse linho para o fabrico de cordas para prender os animais, do mesmo modo como foi reproduzido pelo professor Manuel Nunes Dias ${ }^{31}$.

José Henriques Ferreira comenta que o Marquês de Lavradio enviou o linho para a Cordoaria Real de Lisboa com o objetivo de que fossem realizadas experiências sobre a resistência do novo cordame. Os pareceres da cordoaria não foram favoráveis a produção do linho guaxima. O autor informa que em comparação ao linho cânhamo, o linho guaxima é inferior. Não obstante, João Hopman continuou apostando na utilidade do linho e prosseguiu com a produção e as experiências. Só por esta memória econômica não é possível encadear a ordenação dos fatos que se passaram entre os anos iniciais de produção no final do vice-reinado do marquês e o período de estabilidade do processo produtivo. Para a história da técnica essa etapa se constitui pela automatização dos processos, porque diminui a realização de experiências e testes.

A técnica de beneficiamento se iniciava com o conhecimento do momento de coleta/colheita ${ }^{32}$ da planta no solo. Após a coleta, extraía-se a 'cutícula verde' e a casca podia ser macerada na água. Em seguida, separavam-se as fibras e torciam-nas em fios. A partir desse método foi possível produzir não só cordas, mas também outros tipos de panos para diversos usos. João Hopman supervisionou marinheiros, prisioneiros e outras pessoas para a realização do beneficiamento do linho. Possivelmente, com essa interação, ele foi aprendendo as técnicas que estavam sendo desenvolvidas em conjunto. No Correio Official, João Hopman é chamado de homem ativo, curioso e de gênio cultivador, bem como atesta que fora ele quem começou a produzir oficialmente as cordas com o linho guaxima como empreendimento comercial.

\footnotetext{
${ }^{31}$ DIAS, 1955.

${ }^{32}$ No início da produção ainda não tinha sido estabelecido o plantio do arbusto para realização de colheita. Ele era coletado na natureza de forma silvestre a partir de diversos agentes incumbidos pelo vice-rei Marquês de Lavradio, especialmente, os Mestres de Campo no recôncavo da capital.
} 
Na época o linho mais conhecido e de qualidade vinha da cidade de Riga. José Henriques Ferreira como fora mencionado tinha um conhecimento cosmopolita sobre a flora e fazia parte de uma ampla rede de naturalistas. Ele informa que o linho de Riga é o melhor de toda Europa. A partir do beneficiamento do linho era possível fazer lonas e 'brios/brioes' termo usado por marinheiros para designar cordas para ferrar e colher as velas, consultado no dicionário Vocabulario portuguez \& latino... de Raphael Bluteau (1728). Ainda que se suponha que o linho guaxima não seja bom para os cabos e amarras da Marinha Real, José Henriques Ferreira questiona-se se não seria bom para outros usos de cordas ordinárias, entre outros. Ou seja, aproveitar as qualidades de um linho, cuja árvore nasce em abundância na América. Desse modo, ele ressalta que "[...] a boa economia é cada um remediar-se com o que tem em casa, evitando ir buscar fora: cada gênero tem sua serventia e porque uns são de melhor qualidade não se devem desprezar os de menor $[\ldots]^{\prime 33}$.

No jornal A Luz há uma matéria de 1872 com o título $O$ marquês de Lavradio terceiro vice-rei do Brasil em que se buscou realizar um esboço biográfico do vice-rei. Há um pequeno parágrafo sobre a cordoaria do linho guaxima: “Criou uma fábrica de cordas de guaxima em Mataporcos, sobre a direção de João Hopman, na qual se fizeram cordas de grossuras diferentes para embarcações pequenas e uso das obras particulares" 34 . Aqui é importante notar que a criação da fábrica é atribuída ao marquês. Efetivamente, os testes e experiências se iniciaram no período deste vice-rei, mas seu funcionamento pleno e estável ocorreu na década seguinte.

Informações complementares podem ser conferidas no jornal Correio da Bahia em uma matéria publicada em 1877 com o título Ano Biográfico Brasileiro. Já de início a matéria informa que João Hopman era natural da Inglaterra. O parágrafo prossegue e conclui que ele veio para o Rio de Janeiro em meados do século XVIII, onde se estabeleceu como negociante. Na matéria é mencionado que ele comprou um ‘terreno espaçoso' em São Cristóvão. Trata-se da sua chácara, sítio que fazia diversas experiências, inclusive com o café. Contudo, ele já tinha esse terreno há décadas. A cordoaria de linho guaxima estava localizada no arraial de

\footnotetext{
${ }^{33}$ Correio Official, 1844, p. 3.

${ }^{34}$ A Luz, 1872, p. 321.
} 
Mataporcos que corresponde ao atual bairro do Estácio, o local era próximo de sua chácara em São Cristóvão.

A matéria menciona as experiências com o linho guaxima e o estabelecimento da fábrica de cordoaria. É interessante perceber que esta matéria também não menciona o uso local por pessoas escravizadas e indígenas, nem mesmo utiliza a expressão da memória econômica: 'homem do campo'. Ao contrário, construiu-se em torno do próprio João Hopman uma história que o tornava vulto da inventiva: "Hopman passeando a largos passos pela sua chácara, quebrara a haste de uma guaxima e a torcê-la entre as mãos, notou ao entrar em casa fibras resistentes e fortes bem capazes de servir para cordas e cabos e que dali nascera a indústria que o Marquês vice-rei animou [...]"35.

A matéria menciona que uma das heranças deixadas aos descendentes por João Hopman foi o gosto e a aptidão pelo cultivo de plantas exóticas no Brasil. O jornal ainda menciona uma portaria como comprovação de tal herança, pois o documento foi expedido pelo vice-rei Conde de Rezende em maio de 1798, no qual permitiu que sua filha Norberta Hopman desenvolvesse a cultura caneleira no Rio de Janeiro. João Hopman realmente se envolveu com diversas culturas para exportação e até mesmo consumo local. Na passagem a seguir é reiterado seu interesse amplo por tais cultivos: "Aí começou a cultivar plantas da Europa ou da Ásia, então raríssimas no Brasil, e que ele se aprazia e até se empenhava muito em propagar, dando e oferecendo mudas e sementes" ${ }^{\prime 3}$. O próximo tópico tem por intuito observar de perto as discussões que ocorreram na época, a partir da troca epistolar entre representantes régios e a Corte portuguesa, de manuscritos com registros das experiências, dos relatórios dos vice-reis, bem como da sobredita memória econômica de José Henriques Ferreira.

\footnotetext{
${ }^{35}$ Correio da Bahia, 1877, p. 01

${ }^{36}$ Correio da Bahia, 1877, p. 01
} 


\section{AS FONTES DE ÉPOCA SOBRE AS EXPERIÊNCIAS COM O LINHO GUAXIMA}

No Arquivo Histórico Ultramarino constam algumas fontes que permitem compreender com mais detalhes a fábrica de linho guaxima que foi erigida no decorrer da cronologia deste artigo. Alguns documentos foram utilizados nos trabalhos supramencionados, contudo há documentos, por assim dizer, inéditos que permitem agregar novos conhecimentos sobre a produção do linho guaxima no final do século XVIII. O ofício do vice-rei Marquês de Lavradio 12 de janeiro de 1778 é o primeiro documento oficial de que se tem notícia sobre o linho guaxima conforme ressaltou o professor Manuel Nunes Dias. Neste ofício constam as informações de que os primeiros a fazerem uso do linho foram escravizados e indígenas. Esta apreensão é significativa para estudos de interação cultural e troca de conhecimentos em que se pressupõe um contato mais complexo entre as diversas etnias e grupos sociais. Tal informação colide com a ideia de triunfo individual do personagem divulgada pelo periódico Correio da Bahia, bem como permite acessar indiretamente as dinâmicas sociais em relação ao conhecimento técnico. Ainda assim não se pode ignorar o mérito de João Hopman no aprimoramento da produção do linho e estabelecimento da fábrica para o comércio.

Ainda nesta primeira carta, o marquês informou que, após as cordas terem ficado prontas, entregou-as ao comandante da esquadra com o objetivo de realizar testes para saber a resistência deste novo linho. Os oficiais da Marinha realizaram as experiências e aprovaram os cabos. Logo após, o marquês enviou outras cordas para Lisboa, além de uma arroba do linho 'in natura' para ser produzido na Cordoaria Real e assim fazer todos os exames necessários para atestar a qualidade do linho. Ao finalizar o parágrafo, o vice-rei concluiu que também é possível fazer lonas com o linho e assim tem realizado experiências. Em relação ao João Hopman, o marquês informou que ele era holandês, casado nesta capital, na qual vivia há décadas. No final da década de 1770, os negócios de Hopman não iam bem, mas tinha um histórico pessoal que o autorizava estar à frente do empreendimento, devido ao seu conhecimento e aptidão para desenvolver novas culturas como a plantação do café, a plantação de amoreiras para cultivar o bicho da seda, testes de beneficiamento do linho cânhamo, bem como outras culturas não elencadas pelo marquês, como a introdução da canela como item de exportação. Ademais, de 
acordo com o que fora sobredito no trabalho de Fábio Pesavento, era um homem que fazia parte de uma rede de negócios entre o Rio de Janeiro e Lisboa. Essa rede comercial pode ser constatada também nesta carta, pois, ao propor o privilégio exclusivo para a produção do linho, o marquês sugeriu que se buscasse informações sobre ele na praça comercial lisboeta: "Este homem se chama João Hopman todos o conhecem excelentemente e em Lisboa achará V. Ex. infinitas pessoas que o poderão informar de seu merecimento" 37 .

No final dessa carta há uma mudança sutil no discurso que permite adentrar nos meandros da negociação sobre a criação da fábrica de cordas, porque o fabrico de determinados gêneros não poderia ser manufaturado na colônia. Desse modo, o marquês conduziu a narrativa com intuito de permitir a Rainha refletir sobre a importância deste empreendimento no espaço colonial, entretanto, ele informou que outra opção seria enviar o linho em ramas para realizar o beneficiamento na Cordoaria Real de Lisboa. Nesta parte final da carta é possível reconhecer o representante régio sendo cauteloso ao justificar e solicitar a criação de uma fábrica de cordas no Rio de Janeiro colonial. É interessante salientar que na primeira metade da carta, o marquês não usa a palavra fábrica, só estabelecimento. Somente no momento de justificativa que a palavra fábrica figura na carta: "O meu parecer não se pode conformar com fábricas nas conquistas, porém é certo que esta regra não deve ser tão geral que algumas vezes não tenha a sua exceção"38.

É uma negociação delicada. É preciso lembrar que na gestão da Rainha Maria I, alguns anos depois, 5 de janeiro de 1785, foi publicado um alvará bastante conhecido pela historiografia brasileira em que se proibiu o estabelecimento de fábricas/teares de tecidos finos, exceto: “[...] aqueles dos ditos teares e manufaturas em que se tecem ou manufaturam fazendas grossas de algodão que servem para o uso e vestuário dos negros, para enfardar e empacotar fazendas e para outros ministérios semelhantes [...]"39. É corrente a historiografia mencionar que a produção dos tecidos grossos para as vestimentas dos negros escravizados foi autorizada, mas, aqui é interessante manter o enfoque nos usos para enfardar, empacotar e ministérios semelhantes, pois como foi visto, o linho guaxima era útil para a produção cordas, mas também

\footnotetext{
${ }^{37}$ AHU-Rio de Janeiro, cx. 115, doc. 4. AHU_ACL_CU_017, Cx. 107, D. 8868.

${ }^{38}$ AHU-Rio de Janeiro, D. 8868. Grifo do autor do artigo.

${ }^{39}$ ALVARÁ de d. Maria I que proíbe o estabelecimento de fábricas e manufaturas no Brasil.... Arquivo Nacional. Coleção Junta da Fazenda da província de São Paulo 5 de janeiro de 1785, p. 02.
} 
para lonas e sacos. Embora a citação acima mencione o algodão, o alvará se remete a diversos tipos de tecido, tais como lã, seda, algodão, inclusive linho. Desse modo, infere-se que este alvará não interferiu na fábrica de cordas, panos e sacarias de linho guaxima. Diferentemente foram fechadas 16 fábricas têxteis existentes na capitania do Rio de Janeiro, sendo 13 de homens e 3 de mulheres, como informou Nireu Cavalcanti ${ }^{40}$.

A resposta à carta do marquês foi escrita em Portugal no dia 14 de julho de 1778 pelo secretário de Estado Martinho de Melo e Castro. Ao se referir ao linho guaxima com a palavra 'erva', tornou-se mais difícil encontrar a minuta já que no índex do fundo do AHU, não consta a palavra 'guaxima' ${ }^{41}$. Os autores aqui mencionados não citaram essa carta diretamente, mas supuseram que o linho não fora recebido de forma otimista por conta da segunda carta do marquês escrita no final do ano. Na minuta há a informação de que foram realizados testes na Cordoaria Real de Lisboa e, em comparação com o linho cânhamo da cidade de Riga, a resistência do linho guaxima era inferior. O secretário afirmou que esse linho não poderia ser um item do comércio de exportação. O ofício de resposta escrito 4 de dezembro de 1778 aparece no final do texto Manuel Nunes Dias, pois o marquês iniciou a carta mencionando a minuta do secretário. Nessa minuta, o marquês foi ordenado a se dedicar a plantação do linho cânhamo. Ainda assim, ele tenta explicar que o linho, enviado para Lisboa no início do ano, fora coletado em tempo inapropriado, isto é, estava seco e as cordas foram preparadas sem os conhecimentos necessários: "Bem vê V. Ex. que não pode isto fazer uma prova tão sólida contra o merecimento do mesmo linho" ${ }^{\prime 2}$.

Em resposta à ordem do secretário, o marquês informou que tem atuado também na produção do linho cânhamo e que, se não fosse o conflito ocorrido entre os portugueses e os espanhóis, o estabelecimento teria prosperado, pois o cultivo do linho cânhamo estava se desenvolvendo com êxito na capitania de Rio Grande de São Pedro (atual Estado do Rio Grande do Sul). Ele continua e relembrara que, em dois momentos diferentes, intentou-se produzir o linho cânhamo na América portuguesa. A primeira vez no período do Conde de Bobadela e depois, já no contexto do vice-reinado no Rio de Janeiro, pelo vice-rei Conde da Cunha. No

\footnotetext{
${ }^{40}$ NIREU, 2004.

${ }^{41}$ AHU-Rio de Janeiro, cx. 117, doc. 8. AHU ACL CU 017, Cx. 107, D. 8965.

${ }^{42}$ AHU-Rio de Janeiro, cx. 118, doc. 39. AHU_ACL_CU_017, Cx. 108, D. 9056.
} 
início da gestão de Marquês de Lavradio foi difícil dar continuidade a produção deste linho por conta das sementes que envelheceram e ficaram inférteis no armazém. Só retomou estas atividades quando soube que um navio aportado no Rio de Janeiro, cujo destino era a Índia, levava sementes de diversos tipos de árvore. Ele perguntou se havia semente do linho cânhamo porque queria fazer uma comparação com as velhas sementes que tinha no armazém. E, deste modo, o marquês conseguiu três dúzias da semente, mas só germinaram dez e os pássaros comeram a metade dos pés que brotaram. O que sobrou prosperou até a colheita das sementes que seguiram para a Ilha de Santa Catarina junto com uma instrução de como proceder ao plantio, contudo foi neste momento que ocorreu o dito conflito: "Fez efetivamente a plantação, porém o tempo de se colher foi o da invasão daquela ilha aonde tudo se destruiu, mas constandome que um pequeno lavrador da laguna guardara alguma semente e uma pobre mulher também guardara um pouco de linho [... $]^{\natural 43}$. Dauril Alden destinou uma parte considerável de seu livro para retratar os conflitos diplomáticos e as batalhas militares de portugueses e espanhóis entre $1776-1777^{44}$.

O Marquês de Lavradio finalizou a sobredita carta dizendo que os progressos, dali em diante, dependeriam do seu sucessor. Ele é o primeiro vice-rei a fazer um relatório de sucessão, o qual foi publicado em 1842 na revista do Instituto Histórico e Geográfico Brasileiro (IHGB). Esse relatório permite aprofundar a compreensão do desfecho das ações do marquês na cultura do linho guaxima. Ele repassou a conclusão inicial desfavorável sobre a qualidade do linho para o seu sucessor Luís de Vasconcelos e Sousa no relatório, devido ao fato do arbusto ter sido coletado fora do tempo e a técnica de desfibramento estar em fase experimental, tal como o modo de colocar a substância de alcatrão, a qual o marquês julga essencial para o aperfeiçoamento das cordas. Ele informou também que utilizou o linho em algumas embarcações da esquadra, além de serem utilizadas para içar a aguada e mantimentos do navio Santo Antônio. Outro teste com um maior número de cordas foi realizado na fragata Graça Divina, a qual o marquês enviou para Santa Catarina. Ele concluiu que as suas experiências confirmaram que o linho era útil para várias embarcações e chegou a mencionar o uso em embarcações de tipo sumaca, corveta e iate.

\footnotetext{
${ }^{43}$ AHU-Rio de Janeiro, D. 9056.

${ }^{44}$ ALDEN, 1968.
} 
As experiências com o linho prosseguiram mesmo diante do parecer desfavorável. O marquês enviou uma porção deste linho para a Inglaterra para que fossem elaborados novos testes. Esse evento está registrado na carta argumentativa de 4 de dezembro de 1778 . No relatório também há informações de outros testes com objetivo de comparar com o linho cânhamo: “[...] ordenei ao Provedor da Fazenda que mandasse comprar ao armazém de algum particular um cabo dos que lhe vem da Europa para venderem e que fabricando-se do linho guaxima outro pela mesma bitola se experimentasse um com outro [... "'45. Ao atestar a qualidade, o marquês ordenou que se iniciasse a produção de cordas no Rio de Janeiro. Por fim, o vice-rei insistiu porque, embora as experiências reproduzidas em Lisboa tenham resultado na superioridade do linho cânhamo, a produção do linho guaxima não foi expressamente proibida. Aqui emerge uma especificidade ao que tange o funcionamento da administração colonial, em razão do marquês ter sido somente dissuadido da produção, pois as ordens não foram categóricas em proibir a confecção, mas de reunir esforços para a produção do linho cânhamo. Nesse sentido, a produção continuou para atender as necessidades locais, nas palavras do próprio marquês: “[...] se fazem os cabos ordinários das pequenas embarcações e as cordas brancas. Esta grandíssima utilidade achei bastava só para eu não abandonar um negócio de tanta importância"46.

A maior parte dos historiadores consultados mencionou que o cultivo do linho não deu certo porque não se tornou pauta de exportação. Entretanto, o linho continuou sendo produzido para consumo da cidade, dado que percorrendo a série de documentos do Arquivo Histórico Ultramarino relativa à Capitania do Rio de Janeiro foi encontrada outra carta escrita pelo secretário Martinho de Melo e Castro de 02 de agosto de 1782 ao vice-rei Luís de Vasconcelos e Sousa, na qual ele relatou um novo envio de cordas de linho guaxima pelo João Hopman. Trata-se de documento que demonstra o empenho desse agente em dar continuidade à atividade. O secretário relembrou que na época do Marquês de Lavradio não se estimulou a cultura do linho guaxima por conta do parecer contrário à produção, mas desta vez reconhecia o valor do linho como pode ser conferido no fragmento: “[...] este artigo merece toda atenção e eu recebi

${ }^{45}$ LAVRADIO, Luís de Almeida Portugal, $2^{\circ}$ Marquês de. Relatório do marquês de Lavradio, vice-rei do Rio de Janeiro entregando o governo a Luís de Vasconcelos e Sousa. RIHGB, t. 4, p. 409-486, 1842, p. 472.

${ }^{46}$ LAVRADIO, 1842, pp. 473 
ultimamente uma carta de João Hopman, acompanhada de uma certidão de que remeto a V. Ex. a cópia por onde vejo terem-se fabricado nessa cidade para uso dos armazéns reais, cabos do linho guaxima [...]"47. Esse segundo envio resultou em um parecer favorável da Corte portuguesa, porque as indagações foram no sentido de saber os usos deste novo linho nos Armazéns Reais. Além disso, solicitou o envio de uma porção do linho 'in natura' com uma instrução de como realizar o beneficiamento.

A resposta do vice-rei Luís de Vasconcelos e Sousa foi encontrada no acervo da Livraria da Casa dos Marqueses do Castelo Melhor, salvaguardado pela Biblioteca Nacional do Rio de Janeiro. A carta foi escrita em 14 de setembro 1783, na qual o vice-rei relatou que, no ano de 1777, houve uma escassez de cordas de linho cânhamo para embarcações e o referido marquês procurou animar a cultura a partir do arbusto chamada guaxima. Ele mencionou experiências e os testes para descobrir a resistência desse linho. Nesta carta consta que as experiências foram executadas em um guindaste da Casa do Trem da Artilharia. Atualmente um dos espaços do Museu Histórico Nacional no Rio de Janeiro ${ }^{48}$.

Ainda nesta carta, o vice-rei Luís de Vasconcelos e Sousa reclamou com o secretário Martinho de Melo e Castro sobre a posição de alguns comandantes da esquadra portuguesa ao se negarem a fazer testes com o linho guaxima nas embarcações. Ele informou a dificuldade de aceitação do linho pelo fato de não ter sido produzido no 'estrangeiro'. Desse modo, a falta de interesse dos comandantes em realizar os testes acabam por comprometer a avaliação: "[...] ouvindo deles quase sempre uma reprovação e desprezo total deste linho brasílico, rara vez me tenho deliberado a mandar lhe entregar algum, porque vejo que é inútil e ainda prejudicial toda a experiência feita de má fé $[. . .]^{\prime 49}$. Outro ponto interessante é que o referido João Hopman continuava a realizar experimentos com o linho, pois enterrou no solo com água do mar um pedaço da corda elaborada com o linho guaxima para simular o uso em condição marítima extrema. Nesse momento, o otimismo de João Hopman em exportar o linho guaxima foi reavivado. Em 1784, novas experiências de resistência foram executadas na Cordoaria Real de Lisboa pelo inspetor Luís Antônio de Leiro Seixas Souto Maior, porém as experiências

\footnotetext{
${ }^{47}$ AHU-Rio de Janeiro, cx. 130, doc. 3. AHU_ACL_CU_017, Cx. 119, D. 9673.

${ }^{48}$ CORRESPONDÊNCIA de Luís de Vasconcelos e Sousa a Martinho de Melo e Castro, carta datada de 14 de setembro de 1783 . Biblioteca Nacional do Rio de Janeiro. Localização: 04,04,005, XXXIV.

${ }^{49}$ CORRESPONDÊNCIA, 1783, 04,04,005, XXXIV.
} 
resultaram em outro parecer desfavorável sobre o linho guaxima. Dauril Alden presume que o parecer não foi diferente porque a reputação do inspetor da cordoaria incidiu sobre o resultado ${ }^{50}$, visto que não era a primeira vez que o linho guaxima estava na cordoaria para experiência de resistência.

Ao final do governo, Luís de Vasconcelos e Sousa também escreveu um relatório para o seu sucessor no vice-reinado do Rio de Janeiro, o Conde de Resende. A Revista do IHGB publicou o relatório em 1860. Em relação ao linho guaxima, Vasconcelos e Sousa relatou que a fábrica de cordas estava localizada no arraial de Mataporcos. Era o final do seu mandato, havia transcorrido mais seis anos de funcionamento da cordoaria, após o relatório do inspetor da cordoaria em Portugal. Até o momento da pesquisa para este artigo não foi possível localizar documentos que mencionem o encerramento das atividades dessa cordoaria. No relatório consta que este tipo de cordame tem sido útil para a Marinha do Rio Grande do Sul e a Casa do Trem da Artilharia no Rio de Janeiro: “[...] são estes cabos muito úteis pela abundância que aqui há da primeira matéria pelas poucas despesas e para suprirem outros de que sempre há nos armazéns reais a maior precisão" "51. É interessante notar, a partir da pesquisa do historiador João Fragoso, as novas formas de acumulação no Centro-Sul da América portuguesa no final do século XVIII. O mercado local e entre capitanias era rentoso e equilibrava a balança comercial deficitária entre Rio de Janeiro e Lisboa ${ }^{52}$. Uma pesquisa mais aprofundada pode encontrar documentos que evidenciem um comércio inter-regional de cordas de linho guaxima para além dos usos mencionados pelo vice-rei.

Na Memória sobre a guaxima do médico do marquês José Henriques Ferreira foi possível perceber que o autor utilizou os mesmos dados das experiências realizadas na cidade do Rio de Janeiro e das experiências realizadas na Cordoaria Real de Lisboa com o linho guaxima versus o linho cânhamo. Desde a época do Marquês de Lavradio, tem-se conhecimento que não existe somente uma espécie de guaxima, sendo uma branca e outra vermelha. Nessa memória econômica há uma tabela com os dados dos testes de resistência elaborados com os

\footnotetext{
${ }^{50}$ ALDEN, 1968.

${ }^{51}$ SOUSA, Luís de Vasconcelos e. Relatório do vice-rei do Estado do Brasil: Luís de Vasconcelos ao entregar o governo ao seu sucessor o conde de Resende. RIHGB, t. 23, p. 143-239, 1860, p. 224.

${ }^{52}$ FRAGOSO, João. Mercados e negociantes imperiais: um ensaio sobre a economia do império português (séculos XVII E XIX). História: Questões \& Debates. Curitiba, n. 36, p. 99-127, 2002
} 
diferentes linhos no Rio de Janeiro e em Lisboa ${ }^{53}$. Os dados do Rio de Janeiro foram registrados em manuscrito por João Hopman em 22 de março de 1779 e os dados das primeiras experiências elaboradas em Lisboa foram registrados, em anexo, de uma carta do provedor da Fazenda João Antônio Salter de Mendonça, desembargador da Relação e provedor da Fazenda Real também de $1779^{54}$. Ao conferir o sistema de peso registrado em quintais, arrobas e arráteis nos manuscritos, verifica-se que se tratava dos mesmos resultados publicado na memória econômica em 1789. O registro da experiência elaborada no Rio de Janeiro faz parte de uma exibição pública, na qual participou diversas autoridades entre elas, o próprio vice-rei e o sobredito provedor João Antônio Salter de Mendonça ${ }^{55}$. O evento ocorreu no arraial de Mataporcos espaço onde a fábrica ficaria estabelecida na década de 1780.

José Henriques Ferreira inseriu dois novos itens na tabela de sua memória econômica (7 e 8) que não estão nos dados registrados de 1779. Trata-se respectivamente do linho guaxima vermelha de 12 fios sem alcatrão (7) e com alcatrão (8). É interessante notar que o motivo de enumerar mais dois itens foi porque a corda estava com uma nova forma de beneficiamento que não foi registrado com detalhes técnicos. Entretanto, a corda produzida por João Hopman já continha uma diferença importante em relação ao linho cânhamo desde 1779, pois, ao constatar a menor resistência em relação ao linho cânhamo, João Hopman resolveu introduzir 3 filamentos na corda de guaxima. Quer dizer, a corda de linho cânhamo convencional possui 9 fios, mas, nos registros, as cordas de linho guaxima tanto a branca quanto a vermelha de 9 fios tiveram pouca resistência e, por isso, inseriu-se mais 3 filamentos. As cordas de 12 fios foram produzidas com menos fibra para não exceder o diâmetro de 1 polegada $(2,54 \mathrm{~cm})$ da corda de linho cânhamo de 9 fios, como citado acima no jornal Sete D'Abril: 'linho de igual grossura'. Nos resultados, o autor da memória econômica afirma que a guaxima vermelha de 12 fios com o novo método de beneficiamento e alcatroada referida no item 8 pode substituir o linho cânhamo

\footnotetext{
${ }^{53}$ FERREIRA, José Henriques. Memória sobre a Guaxima. In: Memórias econômicas da Academia Real de Ciências de Lisboa, t. 1, 1789.

${ }^{54}$ CARTA de João Antônio Salter de Mendonça de 07 de março de 1779 e RELATO de teste de resistência realizado com o linho guaxima apresentado por João Hopman 22 de março de 1779. In: Fundo Marquês do Lavradio. Arquivo Nacional.

${ }_{55}$ É interessante notar que Dauril Alden acessou o arquivo privado de Marcos Cláudio Felipe Carneiro de Mendonça doado ao Arquivo Nacional somente em 1995 pela Academia Brasileira de Letras. Possivelmente, Dauril Alden soube da existência desse arquivo particular por conta da publicação da revista do IHGB de 1952, visto que o autor utilizou a revista do instituto fartamente em sua pesquisa. No volume 215 de 1952, Marcos Carneiro de Mendonça publicou um catálogo de documentos históricos de sua coleção com o título: Documentos do arquivo do $2^{\circ}$ marquês do Lavradio e $3^{\circ}$ vice-rei do Brasil. Relação organizada por Marcos Carneiro de Mendonça. Nessa coleção consta digitalizado o relato de experiência e a carta do provedor de 1779. Além disso, consta outra carta enviada por João Hopman ao Marquês de Lavradio em Portugal datada de maio de 1780 .
} 
porque a diferença, ainda que inferior, é considerada pequena em relação ao linho cânhamo de 9 fios. É possível que esta nova forma de beneficiamento e aperfeiçoamento da produção tenha motivado as novas experiências na Cordoaria Real de Lisboa.

A comparação entre a memória econômica, o manuscrito de relato de experiência e o manuscrito anexo na carta do provedor permite inferir que no intervalo dessa década a coleta e o processamento deste linho foi sendo aprimorado a partir de um novo procedimento técnico. Neste texto, circunscreve-se procedimento técnico como técnicas de cultivo e beneficiamento de gênero agrícola. A comparação dos dados nos manuscritos e na publicação permite reconstituir parcialmente o saber-fazer que foi desenvolvido sobre a técnica de produção de cordas na cidade do Rio de Janeiro do final do século XVIII. O novo método de beneficiamento do linho guaxima foi inserido nos itens 7 e 8 da tabela da memória econômica publicada na Academia Real das Ciências de Lisboa.

Até o momento o único documento que se teve acesso sobre o trabalho empregado e o artefato da fábrica de cordas foi uma carta enviada por João Hopman ao Marquês de Lavradio em maio de $1780^{56}$. Um pouco depois do retorno do marquês para Portugal, João Hopman escreveu-lhe e, logo de início notificou que estava enviando quatro pés de laranja selecta pelo comandante da embarcação. Em seguida, escreveu sobre a fábrica de cordas e registrou informações importantes sobre o trabalho e o artefato de beneficiamento. João Hopman informou que prisioneiros estavam trabalhando nas 'rodas da cordoaria'. Ao se referir a roda permite conceber hipoteticamente o formato do artefato utilizado para produzir as cordas. A roda giratória à manivela utilizada para a produção de corda foi adaptada para ralar mandioca e foi muito empregada no período colonial e imperial. Francisco Andrade na dissertação $A$ memória das máquinas: um estudo de história da técnica em São Paulo desenvolveu uma pesquisa importante para ampliar a concepção desses artefatos de beneficiamento agrícola disponíveis, especialmente, no período colonial $^{57}$. A figura 1 é uma prancha publicada na Enciclopédia ou dicionário racional das ciências, artes e ofícios que retrata uma cordoaria na

\footnotetext{
${ }^{56}$ CARTA de João Hopman ao Marquês de Lavradio 04 de maio de 1780. In: Fundo Marquês do Lavradio. Arquivo Nacional.

${ }^{57}$ ANDRADE, Francisco de C. D. de. A memória das máquinas: um estudo de história da técnica em São Paulo. Dissertação de mestrado. Departamento de História do Instituto de Filosofia e Ciências Humanas da Universidade Estadual de Campinas, 2011.
} 
França em meados do século XVIII. Na prancha é possível exemplificar um modelo de roda à manivela utilizado em cordoarias.

Figura 1: Roda giratória à manivela no emprego de manufatura de cordas

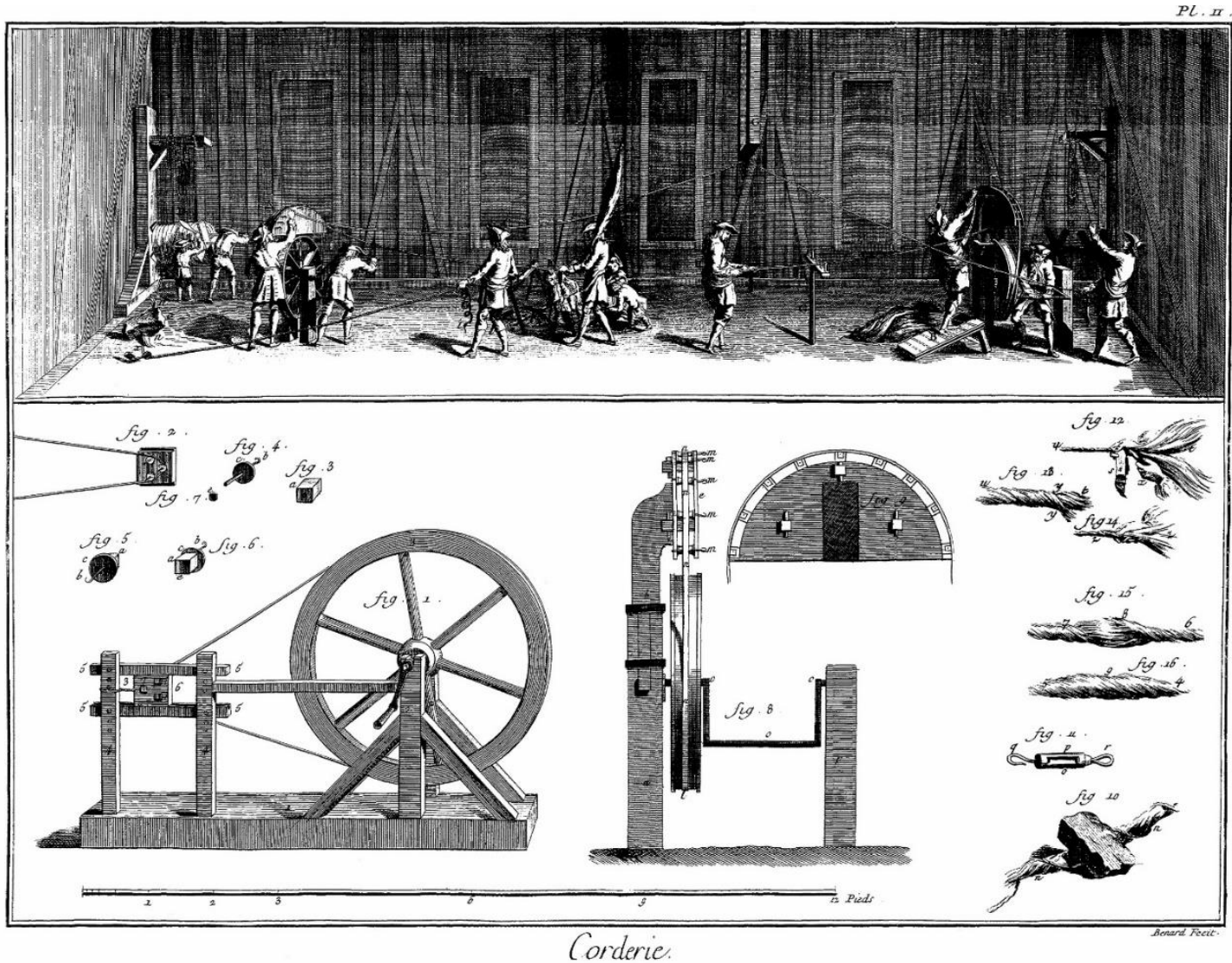

Fonte: Cordoaria. Enciclopédia ou dicionário racional das ciências, artes e ofícios.

Havia passado pouco mais de dez anos que o Marquês de Lavradio enviara aquela primeira carta noticiando a importância deste linho. O linho guaxima não substituiu plenamente o linho cânhamo. Entretanto, o consumo do linho guaxima na cidade do Rio de Janeiro e na Marinha ao sul da América portuguesa ficou registrado nesses documentos da época. Não é de se admirar que Afonso d'Escragnolle Taunay tenha apostado na possiblidade de que corveta relatada pelo viajante espanhol Juan Francisco Aguirre estivesse munida de cordas do linho guaxima. Além disso, é parte do ofício do profissional de história se dedicar as tentativas, seja técnica, econômica ou política, mesmo que determinado ato não tenha prosperado. Afinal, a investida historiográfica é concebida com o resultado final, mas naquele contexto, diversos 
gêneros agrícolas foram incentivados pelos vice-reis, inclusive o café, que se tornou o principal item de exportação no século XIX.

\section{CONSIDERACÕES FINAIS}

As novas culturas agrícolas, desenvolvidas na segunda metade do século XVIII, contribuíram para a exportação comercial diversificada da cidade do Rio de Janeiro. Nos dois primeiros séculos da colonização predominou a exportação do açúcar. Maurício de Almeida Abreu informa que entre 1571 e 1700 existiam 162 engenhos de açúcar na capitania do Rio de Janeiro $^{58}$. No decorrer da primeira metade do século XVIII, o ouro tornou-se o principal item de exportação. Uma passagem no jornal $A$ Luz permite pensar a importância dessa diversificação agrícola que ocorreu na segunda metade do século XVIII: “[...] os navios que até então saíam do Rio de Janeiro quase em lastro ou com alguns couros e açúcar para irem receber carga na Bahia e Pernambuco, puderam obter carga nesta cidade pela abundância de gêneros novos que foram aparecendo"59. Os produtos de pauta de exportação tiveram mais notoriedade no trabalho historiográfico do que a economia de subsistência e de exportação efêmera. Em princípio, o linho guaxima foi um fomento que tinha por intuito a exportação, mas acabou por subsidiar o consumo de cordames em escala local, como na capitania do Rio de Janeiro e na recém-criada capitania de Rio Grande São Pedro. O enfoque voltado para a exportação comprometeu a compreensão desse estabelecimento.

A etapa de inventiva é de suma importância para este trabalho, diferente da etapa automatizada, na qual se diminui a criatividade e ocorre a convenção do processo. A fase criativa permite explorar um conhecimento tácito que envolve tentativa, erro, acerto e aperfeiçoamento. Após esse processo, ocorre a estabilização e o conhecimento desenvolvido inicia uma fase automatizada. $\mathrm{O}$ desmembramento de tais etapas é significativo para estudos de história da técnica que buscam compreender os processos de produção de conhecimento. Ao reunir os documentos da época, foi possível depreender que algumas experiências foram

\footnotetext{
${ }^{58}$ ABREU, Mauricio de Almeida. Geografia Histórica do Rio de Janeiro (1502-1700). 2 vols. Rio de Janeiro: Andrea Jakobsson Estúdio \& Prefeitura do Município do Rio de Janeiro, 2010.

${ }^{59}$ A Luz, 1872, p. 321.
} 
desenvolvidas antes de janeiro de 1778, o que leva, no mínimo, a considerar o ano de 1777 como de escassez do linho cânhamo e início das experiências. Um indício dessa fase inicial foi conferido na correspondência oficial, visto que na carta de julho de 1778, o secretário Martinho de Melo e Castro respondeu ao marquês que o linho guaxima não era apropriado para substituir o linho cânhamo e o marquês, na carta de dezembro do mesmo ano, explicou que o linho fora coletado em momento inoportuno. O secretário de Estado só voltou a ter interesse na corda de linho guaxima na carta de agosto de 1782. Contudo, o empreendimento foi dissuadido após o novo relatório desfavorável do inspetor da cordoaria Antônio de Leiro Seixas Souto Maior em 1784. Do mesmo modo, foi possível perceber a introdução de novas técnicas e métodos de fabricação da corda, a partir do cotejamento dos dados das experiências nos manuscritos de 1779 e a publicação da memória econômica em 1789. Dessa forma, a análise da documentação evidencia que foi se desenvolvendo expertise para coletar o arbusto no tempo apropriado, do mesmo modo, as técnicas de processamento da fibra foram sendo aperfeiçoadas a partir da introdução de filamentos e novos métodos de beneficiamento do linho guaxima.

\section{REFERÊNCIAS}

\section{Fontes}

ARQUIVO HISTÓRICO ULTRAMARINO, Rio de Janeiro, cx. 81, 108, 115, 117, 118 e 130.

ARQUIVO NACIONAL. Alvará de d. Maria I que proíbe o estabelecimento de fábricas e manufaturas no Brasil. Coleção Junta da Fazenda da província de São Paulo 5 de janeiro de 1785, Lisboa. Lavradio.

Carta de João Antônio Salter de Mendonça de 07 de março de 1779. Fundo Marquês do . Carta de João Hopman ao Marquês de Lavradio 04 de maio de 1780. Fundo Marquês do Lavradio.

. Relato manuscrito de teste de resistência realizado com o linho guaxima apresentado por

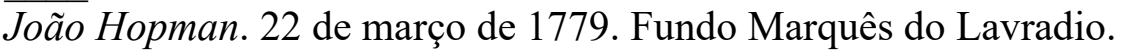

BIBLIOTECA NACIONAL. Correspondência de Luís de Vasconcelos e Sousa a Martinho de Melo e Castro, carta datada de 14 de setembro de 1783. Localização: 04,04,005, XXXIV. 
BLUTEAU, Raphael. Vocabulario portuguez \& latino: aulico, anatomico, architectonico . Coimbra: Collegio das Artes da Companhia de Jesu, 1712 - 1728.

DIDEROT, Denis; D'ALEMBERT, Jean R. Enciclopédia ou dicionário racional das ciências, artes $e$ ofícios. Disponível em: $<$ http://planches.eu/planche jpg_orig.php?nom=CORDERIE\&nr=3>. Acesso em: set. 2021.

HEMEROTECA DIGITAL DA BIBLIOTECA NACIONAL. A Luz. O marquês de Lavradio terceiro vice-rei do Brasil. v.1, 1872. $\overline{1877}$.

Correio da Bahia. Notícias diversas. Ano biográfico brasileiro. João Hopman. ano 7,

. Correio Official (RJ). Memória sobre a guaxima, n. 350, 1844.

. O Sete D'Abril. Rio de Janeiro, n. 191 e 194,1834.

FERREIRA, José Henriques. Memória sobre a Guaxima. In: Memórias econômicas da Academia Real de Ciências de Lisboa, t. 1, 1789.

LAVRADIO, Luís de Almeida Portugal, $2^{\circ}$ Marquês de. Relatório do marquês de Lavradio, vice-rei do Rio de Janeiro entregando o governo a Luís de Vasconcelos e Sousa. RIHGB, t. 4, p. 409-486, 1842.

SOUSA, Luís de Vasconcelos e. Relatório do vice-rei do Estado do Brasil: Luís de Vasconcelos ao entregar o governo ao seu sucessor o conde de Resende. RIHGB, t. 23, p. 143-239, 1860.

\section{Obras Gerais}

ABREU, Mauricio de Almeida. Geografia Histórica do Rio de Janeiro (1502-1700). 2 vols. Rio de Janeiro: Andrea Jakobsson Estúdio \& Prefeitura do Município do Rio de Janeiro, 2010.

ALDEN, Dauril. Royal Government in Colonial Brazil. University of California Press, 1968.

ANDRADE, Francisco de C. D. de. A memória das máquinas: um estudo de história da técnica em São Paulo. Dissertação de mestrado. Departamento de História do Instituto de Filosofia e Ciências Humanas da Universidade Estadual de Campinas, 2011.

CAVALCANTI, Nireu. O Rio de Janeiro setecentista: a vida e a construção da cidade da invasão francesa até a chegada da Corte. Rio de Janeiro: Zahar, 2004.

DIAS, Manuel Nunes. Notícias da cultura industrial da guaxima no Brasil nos fins do século XVIII. Revista de História. v. 11 n. 24, pp. 419-423, 1955. 
FRAGOSO, João. Mercados e negociantes imperiais: um ensaio sobre a economia do império português (séculos XVII E XIX). História: Questões \& Debates. Curitiba, n. 36, p. 99-127, 2002.

FREITAS, Eugénio Cunha e. Familiares do Santo Ofício no Porto. Revista de História, Porto, v.2, pp. 229-236, 1979.

KURY, Lorelai. Homens de ciência no Brasil: impérios coloniais e circulação de informações (1780-1810). História, Ciências, Saúde - Manguinhos, v. 11, s. 1, 2004.

LIMA, Heitor Ferreira. História político-econômica e industrial do Brasil. São Paulo: Companhia Editora Nacional, 1970.

LORENZI, Harri. Árvores brasileiras: manual de identificação e cultivo de plantas arbóreas nativas do Brasil. São Paulo: Editora Plantarum, 2009.

LUCA, Tânia Regina de. A história dos, nos e por meio dos periódicos. In: PINSKY, Carla Bassanezi (Org.). Fontes Históricas. São Paulo: Contexto, 2005.

MARQUES, Vera R. B. Escola de homens de ciências: a Academia Científica do Rio de Janeiro, 1772-1779. Editora UFPR: Educar, Curitiba, n. 25, p. 39-57, 2005.

PATACA, Ermelinda M. Terra, água e ar nas viagens científicas portuguesas (1755-1808). Tese de Doutorado. São Paulo: Instituto de Geociências/UNICAMP, 2006.

PESAVENTO, Fábio. Um pouco antes da Corte: a economia do Rio de Janeiro na segunda metade do Setecentos. Tese de Doutorado. Universidade Federal Fluminense, 2009.

REIS, Alexander Lima: Os inspetores da Mesa de Inspeção do Rio de Janeiro: Jerônimo Vieira de Abreu e João Hopman (1783-c.1800). Anais do $17^{\circ}$ Seminário Nacional de História da Ciência e da Tecnologia, 2020.

SILVA, Maria Beatriz N. da. Cultura letrada e cultura oral no Rio de Janeiro dos vice-reis. São Paulo: Editora Unesp, 2013.

WEHLING, Arno. O fomentismo português no final do século XVIII: doutrinas, mecanismos, exemplificações. RIHGB, v. 316, pp.170-279, 1977.

Recebido em: 22/05/2021 - Aprovado em: 27/09/2021 